\title{
Plantwide Control: A New Design Procedure and Its Application at Liquefied Petroleum Gas Facility (LPGF) Plant
}

\author{
Toto Haksoro*, Safira Firdaus Mujiyanti, Aulia Siti Aisjah, and Totok Ruki Biyanto \\ Department of Engineering Physics, Institut Teknologi Sepuluh Nopember, \\ Jl. Teknik Kimia, Sukolio, Surabaya 60111, Indonesia
}

\begin{abstract}
Natural Gas is the cleanest source of fossil energy, resulting in lower carbon emissions from coal and oil. In gas processing, the process done to separate the product composition is the fractionation process. In the gas industry, facilities/parts that are specifically to perform the process are called liquefied petroleum gas Facility plant (LPGF). Process Control is the key to a safe and profitable process industry. The Plantwide control is a structural design and control strategy for the factory as a whole. The preferred control method on this final task is the PID for regulatory control as well as the decentralized supervisory control for supervisory control and the real time optimizer for its optimization. The new plantwide control procedure can increase the profit in the process liquefied petroleum gas facility plant up to USD $643 \mathrm{~h}^{-1}(3 \%)$ and decreased energy use by USD $5 \mathrm{~h}^{-1}(5.16 \%)$. The application of the Plantwide control on the liquefied petroleum gas facility is also able to produce a stable system response when the interruption of the feed flow rate changes. This is demonstrated by decreasing slurries time and maximum overshoot as well as eliminating steady-state errors.
\end{abstract}

Keywords: Distillation column, optimization, control strategy, stability.

\section{Introduction}

The world's need for primary energy continues to increase. However, experts are still struggling to find a new source of energy so that the fossil energy source still holds the dominant role in the future. Natural Gas is the cleanest source of fossil energy, resulting in lower carbon emissions from coal and oil. The global warming issue causes the demand for natural gas to increase as a clean energy source [1].

Natural Gas is a mixture of hydrocarbons such as methane, ethane, propane, butane, and higher fraction. In gas processing, the process done to separate the product composition is the fractionation process. The fractionation process is performed on fractionation units consisting of column Deethanizer, Depropanizer, and Debutanizer. The fractionation

\footnotetext{
*Corresponding author: tohaksoro@gmail.com
} 
process is based on the difference in volatility, also called distillation. In the gas industry, facilities/parts that are specifically to perform the process are called Liquefied Petroleum Gas Facility Plant (LPGF) [2].

The use of distillation columns is rapidly increasing in the process industry and the complex dynamics of operating conditions require better process control [3]. Process control is the key to a safe and profitable process industry. In addition, the performance of process control can produce optimum energy use as well as stable against interference [4]. There are various distillation columns and the type of control structures. The selection of the control structures is influenced by a variety of factors, namely volatility, product purity, reflux ratio, column pressure, energy prices, and the composition of the bait [5]. Above, in one of the columns in the LPGF has a multi-effect prefractionator which causes the heat integration and material recycle [6].

The Plantwide control (PWC) is a structural design and control strategy for the plant as a whole [7]. There is a wide range of design procedures in the implementation of PWC starting from Page S. Buckley which states that in the selection of control pairs should consider where the production rate is determined and inventory control. In this study there is still no systematic procedure for the application of PWC [8]. Luyben states there are nine systematic steps to design procedures for process operations. In this procedure, the drawback is that the economic side is ignored [9]. Skogestad states the PWC procedure consists of four top-down steps and three bottom-up steps. This procedure is given the name of the economic PWC to distinguish between Luyben's previous procedure [10]. Skogestad's PWC procedure has been widely used in the industry, such as the reactorseparator-Recycle process [11], Tennessee Eastman process [12], and the grinding mill circuits [13]. The implementation of economical PWC has also been applied to serial processes, consisting of three neutralization processes [14].

The case of LPGF which is a problem in this final task has changes in operating conditions but the use of energy is not optimal. Therefore, the use of the PWC owned by Skogestad will answer about achieving optimal plant from the economy if it is given interference and produces a stable control system. The preferred control method on this final task is the PID for regulatory control as well as the decentralized supervisory control for supervisory control and the real Time Optimizer (RTO) for its optimization. The second problem is that there is no link between the top-down and bottom-up of Skogestad's PWC procedure. It is necessary to modify the procedure based on the economic PWC in order to connect the two. In previous studies, the implementation of PWC in the distillation column was only at the control strategy stage. In this final assignment, PWC design will be conducted at the LPGF process to the RTO level in order to optimize product quantity, desired composition and optimum energy usage.

\section{Methodology}

\subsection{Liquefied Petroleum Gas Facility Plant (LPGF) plant model}

The data taken is the component data and configuration of equipment needed to model the process in the Liquefied petroleum gas facility plant.

\subsubsection{Deethanizer column-based design conditions}

The Deethanizer column has the following specifications

Size : $2350 \mathrm{~mm} / 1600 \mathrm{~mm} \times 43287 \mathrm{~mm}$

Number of Tray: 50 (tray feed: $15 \& 40$ )

The following is a process diagram of the deethanizer column. 


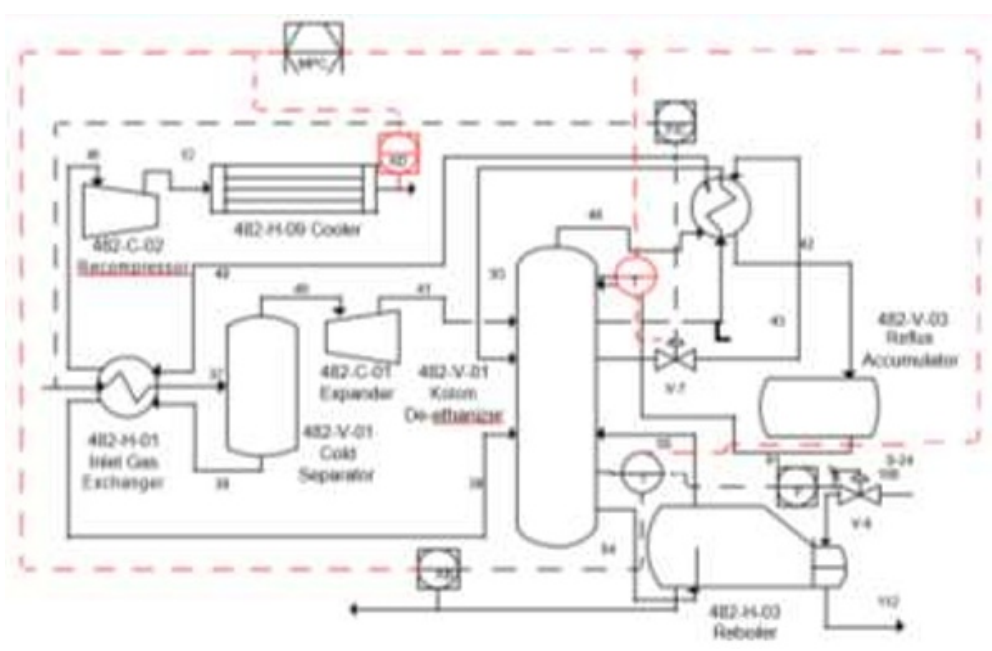

Fig 1. Deethanizer column process diagram.

The details of the deethanizer column studied in the form of operating conditions and energy use can be seen in Table 1 to Table 3 as follows.

Table 1. Specification of deethanizer column

\begin{tabular}{|c|c|c|c|c|}
\hline Specification & Feed 1 & Feed 2 & Top & Bottom \\
\hline Operating Press. $($ barg) & 21.7 & 21.9 & 21.6 & 21.9 \\
\hline Operating Temp. $\left({ }^{\circ} \mathrm{C}\right)$ & -72.42 & 42.22 & -80.89 & 74.4 \\
\hline
\end{tabular}

Table 2. Parameters and data flow in the deethanizer column

\begin{tabular}{|c|c|c|c|c|}
\hline & Unit & Feed & Distilate & Bottom \\
\hline Flowrate & $\mathrm{kg} \mathrm{h}^{-1}$ & 150481 & 123854 & 26627 \\
\hline Temperature & ${ }^{\circ} \mathrm{C}$ & 45 & 41.1 & 79.9 \\
\hline Pressure & bar & 62.1 & 19.1 & 20.4 \\
\hline
\end{tabular}

Table 3. Deethanizer column load specifications

\begin{tabular}{|c|c|c|}
\hline Unit & Condenser (from specification) & Reboiler (from calculation hot oil) \\
\hline $\mathrm{kW}$ & 1696 & 2124 \\
\hline Type & Air Cooler & Kettle \\
\hline
\end{tabular}

\subsubsection{Depropanizer column based on design conditions}

The Depropanizer column has the following specifications

Size: $2000 \mathrm{~mm} \times 37026 \mathrm{~mm}$

Number of Tray: 50 (tray feed: 32 )

The following is a process diagram from the depropanizer column. 


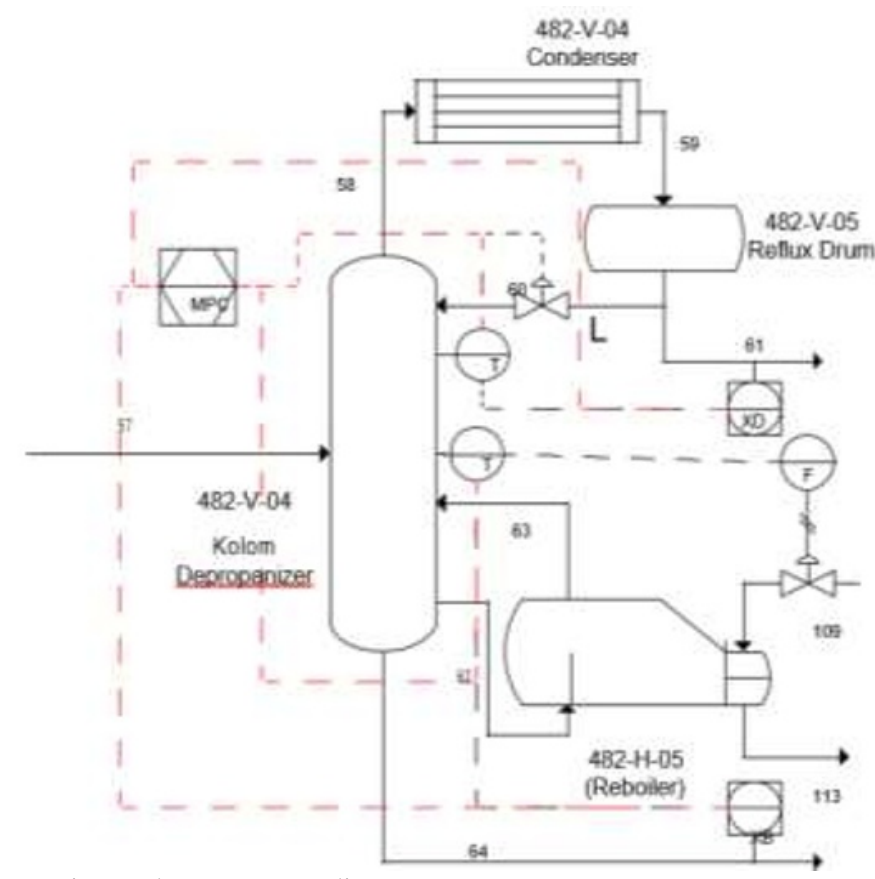

Fig 2. The depropanizer column process diagram.

The details of the depropanizer column can be seen in the Table 4 to Table 6 below.

Table 4. Specifications of depropanizer

\begin{tabular}{|l|l|l|l|}
\hline Specification & Feed & Top & Bottom \\
\hline Operating Press. (barg) & 16.4 & 16.2 & 16.4 \\
\hline Operating Temp. $\left({ }^{\circ} \mathrm{C}\right)$ & 69.12 & 48.78 & 104.53 \\
\hline
\end{tabular}

Table 5. Parameters and depropanizer column flow data

\begin{tabular}{|l|l|l|l|l|}
\hline & Unit & Feed & Distilate & Bottom \\
\hline Flowrate & $\mathrm{kg} \mathrm{h}^{-1}$ & 26627 & 13422 & 13205 \\
\hline Temperature & ${ }^{\circ} \mathrm{C}$ & 70.2 & 48.3 & 110.6 \\
\hline Pressure & bar & 16.4 & 20 & 13.205 \\
\hline
\end{tabular}

Table 6. Depropanizer column load specifications

\begin{tabular}{|l|l|l|}
\hline Unit & Condenser (from specification) & Reboiler (from calculation Qhotoil) \\
\hline $\mathrm{kW}$ & 3452 & 3439 \\
\hline Type & Air Cooler & Kettle \\
\hline
\end{tabular}

\subsubsection{Debutanizer column based on design conditions}

The Debutanizer column has the following specifications

Size: $1400 \mathrm{~mm} \times 34903 \mathrm{~mm}$

Number of Tray: 48 (tray feed: 26)

Following is the process diagram of the debutanizer column 


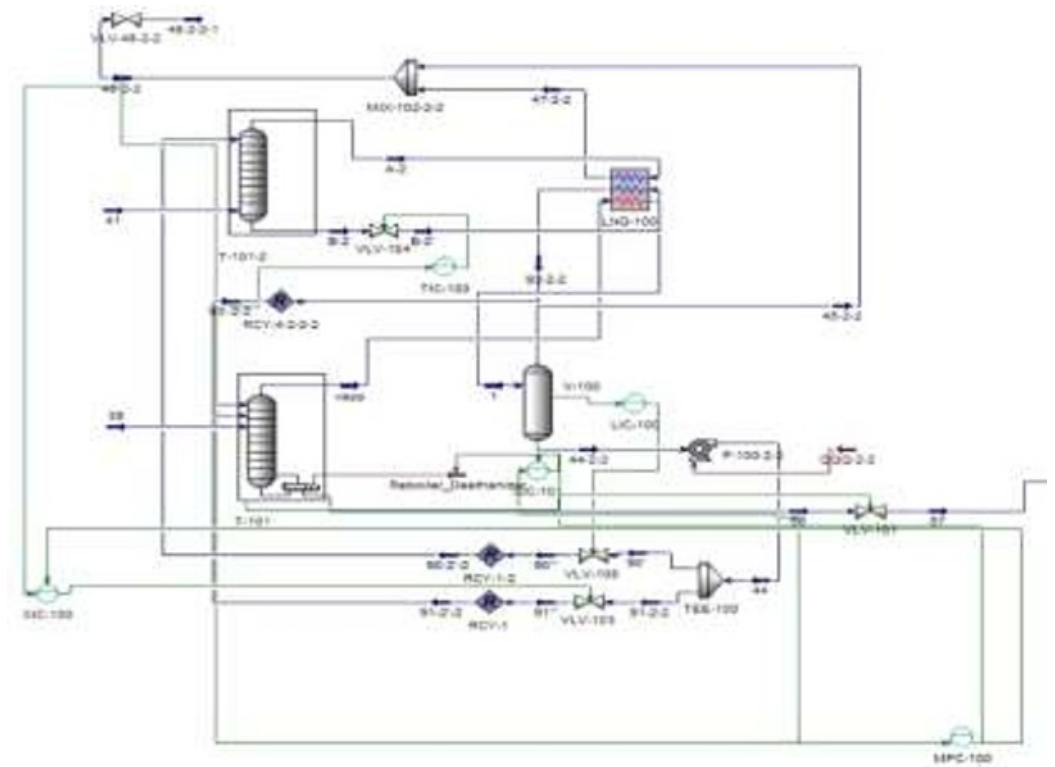

Fig 3. Deethanizer modeling in HYSYS.

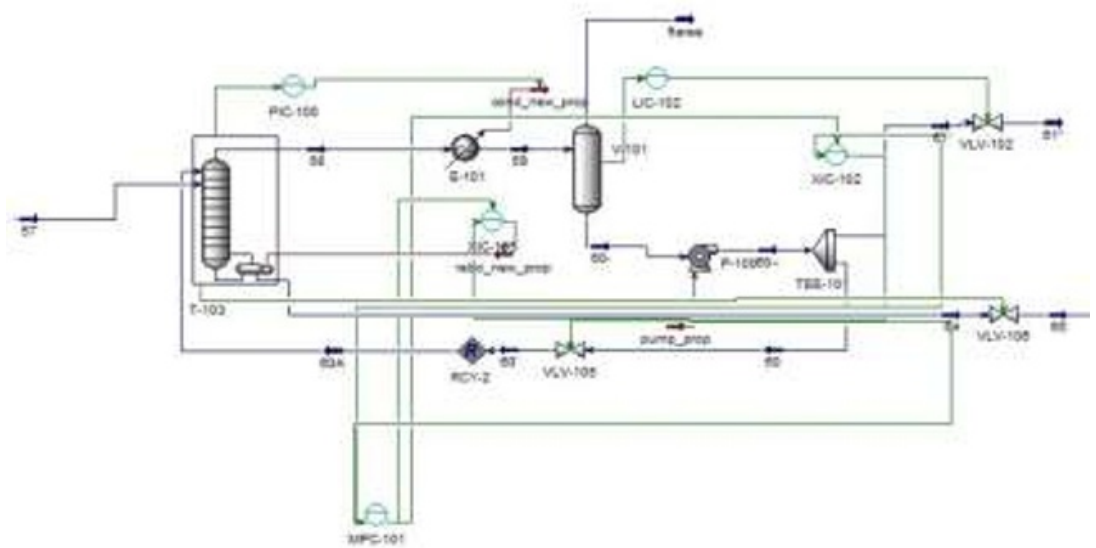

Fig 4. Debutanizer modeling in HYSYS.

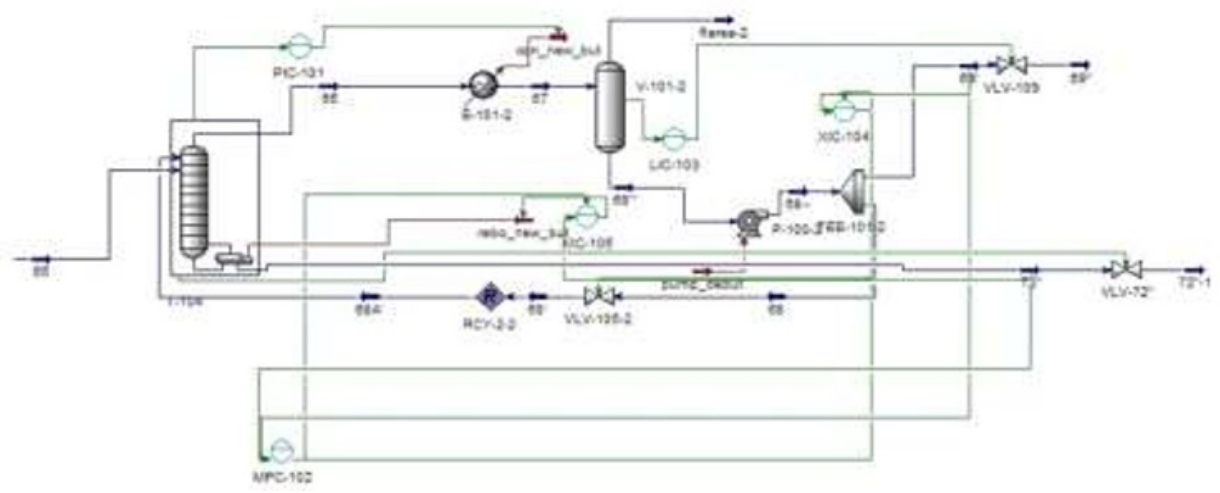

Fig 5. Depropanizer modeling in HYSYS

The model is based on the existing design data and operating conditions using mass and energy equilibrium in HYSYS. The model that has been made is validated by operating 
conditions. The modeling and validation results for the deethanizer column by giving the same feed and energy produce distillates and lower products as shown in Table 7 to Table 8 .

Table 7. Validation results on the flow of deethanizer column distillate products

\begin{tabular}{|l|c|c|c|c|}
\hline \multicolumn{1}{|c|}{ Property } & Unit & Design & Simulation & Error \\
\hline Flow & $\mathrm{kg} \mathrm{h}^{-1}$ & 123751 & 123800 & $0 \%$ \\
\hline Temperature & ${ }^{\circ} \mathrm{C}$ & -56.1 & -55.36 & $1 \%$ \\
\hline Pressure & barg & 20.9 & 21.3 & $2 \%$ \\
\hline Composition & $\%$ mole & 5.775 & 5.81 & $0 \%$ \\
\hline
\end{tabular}

Table 8. Validation results on the product flow of the bottom deethanizer column

\begin{tabular}{|l|c|c|c|c|}
\hline \multicolumn{1}{|c|}{ Property } & Unit & Design & Simulation & Error \\
\hline Flow & $\mathrm{kg} \mathrm{h}^{-1}$ & 26916 & 26820 & $0 \%$ \\
\hline Temperature & ${ }^{\circ} \mathrm{C}$ & 81.7 & 82.69 & $1 \%$ \\
\hline Pressure & barg & 21.9 & 21.9 & $0 \%$ \\
\hline Composition & $\%$ mole & 2.599 & 1.85 & $1 \%$ \\
\hline
\end{tabular}

\subsection{Plantwide control procedure}

PWC involves one or several systems and strategies used to control the plant, where there are interconnected operating units. Three types of operating units that are usually a problem in the plant so that PWC is needed, among others, is the presence of recycled materials, integration of heat and various chemical components. The objectives of the PWC itself include achieving safe and smooth operating conditions, being able to maintain product quality with interference, being able to operate automatically at all times without needing more attention from the operator, meeting environmental restrictions such as dangerous gas emissions and so on. In achieving this goal, there are many PWC procedures developed. Two procedures that are quite popular in the industry today are Luyben's PWC procedures and Skogestad's economic PWC procedures.

Designing the LPGF Plant system by modifying the two most widely used plantwide control methods belonging to Luyben and Sigurd Skogestad. In the Luyben method, the sequence of work from the top down but still does not consider the economic side. Whereas the method proposed by Skogestad has considered the economic side but the sequence of work still uses the top-down and bottom-up methods. Therefore, modifications of the two existing methods are needed, namely the consideration of the economic elements and the sequence of the process. Following are the steps:

\subsubsection{Determine of objective function}

The objective function used is the maximum quality and quantity of each product (methane, ethane, propane and butane) and energy use in a minimum reboiler with minimum quality limits on each product and maximum energy that can be produced by each reboiler. each distillation column. Determination of this objective function takes the objective function of Skogestad while the objective function of Luyben still does not consider the economic side. The following is the objective function used in this wide control plant (Equation 1).

$$
I_{\max }=\text { Product selling results }- \text { Reboiler operating costs }
$$


In this objective function, the energy price refers to the OPEC standard reference for the energy used in the form of crude oil (USD 39.78 barrel $^{-1}$ ), the price of ethane (USD $7.5 \mathrm{mmbtu}^{-1}$ ), the price of propane (USD $510 \mathrm{MT}^{-1}$ ), butane prices (USD $600 \mathrm{MT}^{-1}$ ), and naphtha prices (USD $456 \mathrm{MT}^{-1}$ ). In this objective function, boundaries are chosen in the form of quality from product composition. For the composition limits, according to the design of the LPGF plant, which is 0.058 for ethane, 0.96 for propane, and 0.51 for butane.

\subsubsection{Identify degree of freedom (DOF)}

In principle, all existing systems can be presented through mathematical equations consisting of DOF variables or degrees of freedom in a system is a representation of variables in the system, where the results must be specific before the remaining variables can be calculated. The DOF equation is given in Equation (2).

$$
\text { DOF }=\text { Number of variables }- \text { Number of independent equations }
$$

The amount of degree of freedom (DOF) is calculated by looking for the difference between the number of variables present with the number of equations in the process in the LPGF. The identification of the degree of freedom (DOF) is the same as the identification of Skogestad and Luyben. By reducing the value of the number of variables to the number of equations, the DDOF value obtained is 192 reduce with 177 which is 15 DDOF.

At the plant there are six elements of liquid level that must be controlled (reflux accumulator and reboiler on each distillation column), one temperature must be maintained (in the heat exchanger column deethanizer), two pressures must be maintained (upper part in depropanizer column and debutanizer), then there are only two DOFs left for each column.

\subsubsection{Determine of throughout manipulator (TPM)}

The throughout manipulator (TPM) location is determined at the output flow rate of the control valve according to the design at the plant which is located after the well. Determination of the rate of production is the same as that of Skogestad and Luyben.

\subsubsection{Determine of economical controlled variable}

The economical controlled variable is the flow rate of each product, the quality of the distillate and the bottom of the product and the energy produced by the reboiler in each distillation column (deethanizer, depropanizer, and debutanizer). Determination of this economic variable is the same as the main control variable at Plantwide of Skogestad which considers the economic side. Determination of these economic variables refers to variables that have a direct effect on profit-oriented objective functions.

\subsubsection{Process integration}

In this process, a variable control structure that is related to inventory control and variables that will be disturbance is determined. Determination of the same variable control structure with plantwide owned by Luyben accompanied by determination of the disturbance. Then the PID control structure is determined and secondary variables in the form of levels and pressures on the three distillation columns in LPGF and the disturbance that occurs is the rate of the components of the feed in the actual state. 
Table 9. Disturbance given to LPGF plant

\begin{tabular}{|c|r|}
\hline Disturbance & \multicolumn{1}{|c|}{ Value } \\
\hline Mass flow rate $39\left(\mathrm{~kg} \mathrm{~h}^{-1}\right)$ & 9452 \\
\hline Mass flow rate $41\left(\mathrm{~kg} \mathrm{~h}^{-1}\right)$ & 45720 \\
\hline
\end{tabular}

\subsubsection{Supervisory Control Layer}

The supervisory controller chosen in this study is decentralized supervisory control that will provide optimal set point changes in the regulatory control layer (PI/PID). The supervisory control layer is the same as Skogestad's PWC and controls each loop in Luyben's PWC. The supervisory control design used in this final project is decentralized supervisory control that is already available on HYSYS by using validated first order data models. The model and results of first order model data validation can be seen in Table 10 .

Table 10. Gain (Kp) and time constant $(\tau)$ at liquefied petroleum gas facility

\begin{tabular}{|c|c|c|c|c|}
\hline $\begin{array}{c}\text { Distillation } \\
\text { Column }\end{array}$ & Gain & Kp & $\tau$ (min) & RMSE \\
\hline \multirow{4}{*}{ Deethanizer } & G11 & 0.92 & 11.6 & $3.5 \times 10^{-4}$ \\
\cline { 2 - 5 } & G12 & 0.87 & 7.0 & $2.0 \times 10^{-5}$ \\
\cline { 2 - 5 } & G21 & 0.94 & 17.4 & $1.7 \times 10^{-4}$ \\
\cline { 2 - 5 } & G22 & 0.93 & 13.4 & $8.5 \times 10^{-8}$ \\
\hline \multirow{5}{*}{ Depropanizer } & G11 & 0.70 & 2.8 & $4.3 \times 10^{-4}$ \\
\cline { 2 - 5 } & G12 & 0.62 & 2.1 & $5.5 \times 10^{-5}$ \\
\cline { 2 - 5 } & G21 & 0.91 & 10.8 & $1.7 \times 10^{-4}$ \\
\cline { 2 - 5 } & G22 & 0.94 & 15.5 & $7.5 \times 10^{-5}$ \\
\hline \multirow{5}{*}{ Debutanizer } & G11 & 0.92 & 12.3 & $1.2 \times 10^{-4}$ \\
\cline { 2 - 5 } & G12 & 0.83 & 5.5 & $3.8 \times 10^{-5}$ \\
\cline { 2 - 5 } & G21 & 0.90 & 9.1 & $2.5 \times 10^{-5}$ \\
\cline { 2 - 5 } & G22 & 0.87 & 7.1 & $3.2 \times 10^{-6}$ \\
\hline
\end{tabular}

\subsubsection{Optimization}

Optimization is done by using Real Time Optimizer (RTO). In this final project, optimization is done using RTO that is in HYSYS with the main objective to achieve the objective function that has been determined. This optimization layer is the same as optimization on PWC Skogestad and Luyben.

\subsection{System performance testing}

Plantwide control testing by giving interference to the feed flow according to the reality in the field and seeing the response to the distillate composition, distillate flow rate, and energy use to the feed stream. 


\section{Results and discussions}

\subsection{Optimization result in steady state condition}

The optimization that has been done by giving changes to the feed flow rate from $150481 \mathrm{~kg} \mathrm{~h}^{-1}$ to $55171 \mathrm{~kg} \mathrm{~h}^{-1}$ or $100 \%$ to $37 \%$ obtained by the change obtained can be seen in Table 11 to Table 13. Plantwide control design on the liquefied petroleum gas facility will be compared with the PID system used in existing liquefied petroleum gas facilities.

Table 11. Comparison of the rate of product in the LPGF system

\begin{tabular}{|c|c|c|c|c|c|c|}
\hline \multirow{2}{*}{$\begin{array}{c}\text { Distillation } \\
\text { Column }\end{array}$} & \multicolumn{2}{|c|}{ Feed $\left(\mathrm{kg} \mathrm{h}^{-1}\right)$} & \multicolumn{2}{c|}{ Distillate poduct $\left(\mathrm{kg} \mathrm{h}^{-1}\right)$} & \multicolumn{2}{c|}{ Bottom product $\left(\mathrm{kg} \mathrm{h}^{-1}\right)$} \\
\cline { 2 - 7 } & PID & PWC & PID & PWC & PID & PWC \\
\hline Deethanizer & 55171 & 55171 & 43354 & 43988 & 11816 & 11776 \\
\hline Depropanizer & 11816 & 11776 & 4821 & 4998 & 6995 & 6778 \\
\hline Debutanizer & 6995 & 6778 & 3481 & 3994 & 3514 & 2784 \\
\hline
\end{tabular}

Table 12. Comparison of energy consumption in LPGF system

\begin{tabular}{|c|c|c|c|c|}
\hline \multirow{2}{*}{$\begin{array}{c}\text { Distillation } \\
\text { Column }\end{array}$} & \multicolumn{2}{|c|}{ Reboiler energy $\left(\mathrm{kJ} \mathrm{h}^{-1}\right)$} & \multicolumn{2}{c|}{ Total of energy } \\
\cline { 2 - 5 } & PID & PWC & PID & PWC \\
\hline Deethanizer & 2386077 & 3543450 & 8491677 & 9649050 \\
\hline Depropanizer & 6189981 & 1544670 & 18617181 & 13971870 \\
\hline Debutanizer & 1997889 & 4940000 & 8499489 & 11441600 \\
\hline
\end{tabular}

Table 13. Comparison of profit and operating costs on the LPGF system

\begin{tabular}{|c|c|c|}
\hline Objective $\left(\mathrm{USD} \mathrm{h}^{-1}\right)$ & PID & PWC \\
\hline Product & 20961 & 21599 \\
\hline Operational cost & 93 & 88 \\
\hline Profit & 20868 & 21511 \\
\hline
\end{tabular}

This shows that by applying the PWC on the plant it will increase profit by USD $2436 \mathrm{~h}^{-1}(10.78 \%)$ and reduce energy use by USD $5 \mathrm{~h}^{-1}(5.16 \%)$.

\subsection{Performance testing result}

The system performance after the PWC is applied is tested by looking at its objective function. The value of the own objective function in the PWC is obtained by changing the disturbance variable (DV) where in this final project the flow rate drops by $63 \%$ at time $\mathrm{t}=900 \mathrm{~s}$. The plot of changes in feed flow can be seen in Figure 6. 


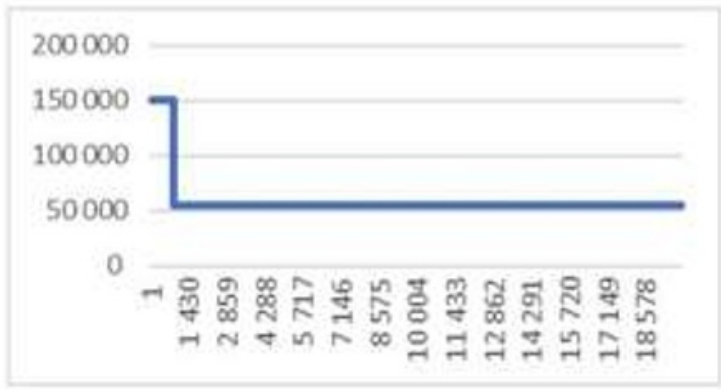

Fig 6. Disturbance at feed.

While the system performance can be seen from the response that the system has to the interference given.

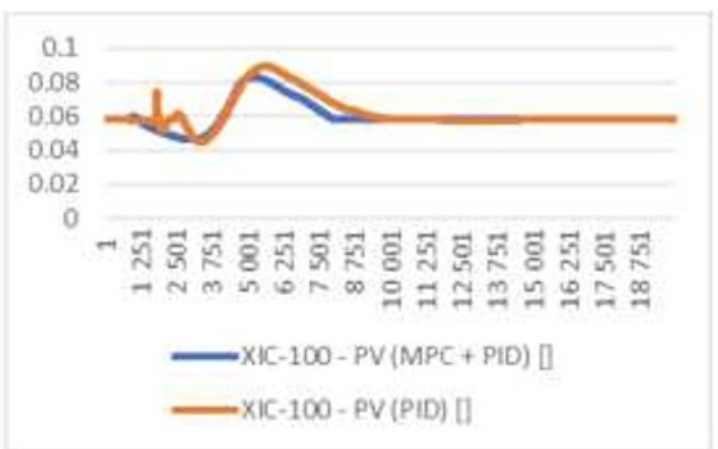

Fig 7. Response of ethane composition (deethanizer).

Figure 7 shows the response of the ethane composition to the deethanizer column distillate. From the picture, it can be concluded that the control response if given PID control as a regulatory control plus decentralized supervisory control as supervisory control will be better able to maintain the given set point. This can be seen from the time to reach a faster set point and a smaller overshoot compared to if the control response only uses PID.

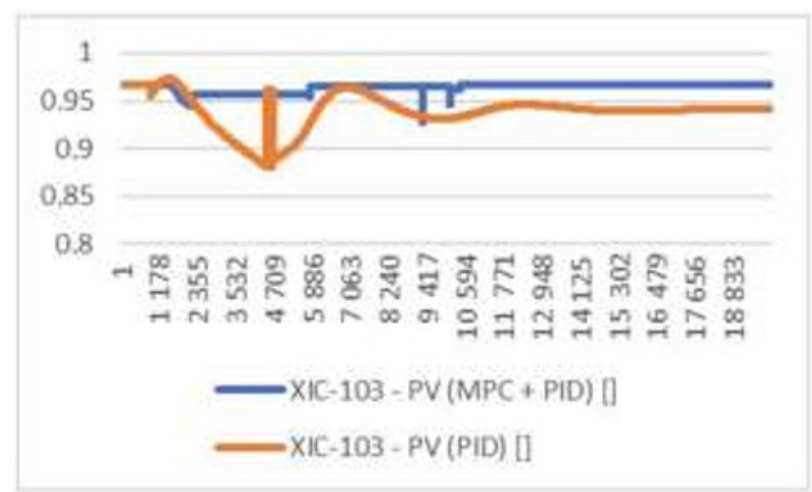

Fig 8. Respons of propane compostion (depropanizer). 


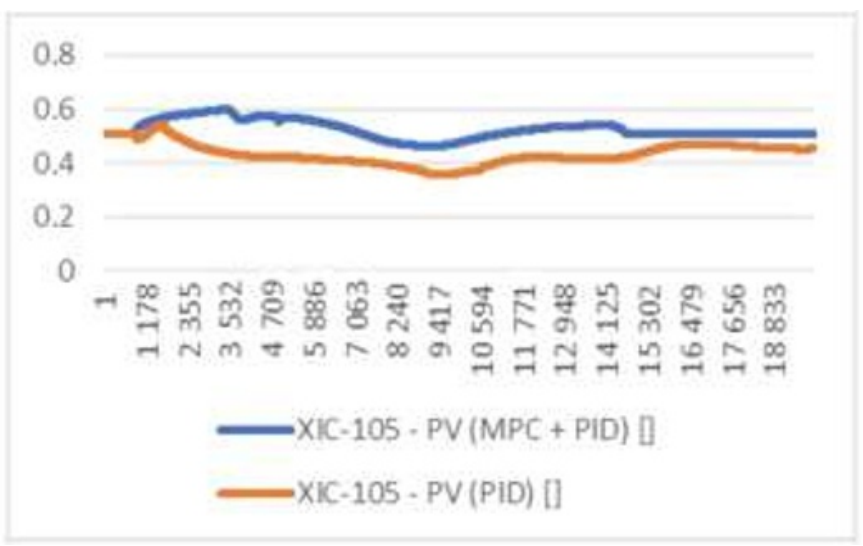

Fig 9. Respons of butane composition (debutanizer).

Figure 8 shows the response of the composition of propane to the depropanizer column distillate. From the picture, it can be seen that the control response if given PID control as a regulatory control plus decentralized supervisory control as supervisory control is better able to maintain the given set point. It can be seen that the response is able to reach the set point again compared to the control response using only PID that is unable to reach the set point.

Figure 9 shows the response of the butane composition to the debutanizer column distillate. From the picture, it can be seen that the control response if given PID control as a regulatory control plus decentralized supervisory control as supervisory control is better able to maintain the given set point. It can be seen that the response is able to reach the set point again compared to the control response using only PID that is unable to reach the set point. The value of settling time, maximum overshoot, and steady state error can be seen in Table 14.

Table 14. Comparison of response characteristics in the LPGF system

\begin{tabular}{|c|c|c|c|c|c|c|}
\hline \multirow{2}{*}{$\begin{array}{c}\text { Distillation } \\
\text { column }\end{array}$} & \multicolumn{2}{|c|}{ Settling time (s) } & \multicolumn{2}{c|}{ Maximum overshoot (\%) } & \multicolumn{2}{c|}{ Error steady state (\%) } \\
\cline { 2 - 7 } & Non-PWC & PWC & Non-PWC & PWC & Non-PWC & PWC \\
\hline Deethanizer & 227.3 & 120.6 & 3.1 & 2.5 & 0.05 & 0 \\
\hline Depropanizer & 241.2 & 158.6 & 8.6 & 0.2 & 2.52 & 0 \\
\hline Debutanizer & 304.6 & 172.1 & 15.6 & 9.0 & 5.71 & 0 \\
\hline
\end{tabular}

From Table 14 it can be seen the characteristics of the composition response in the liquefied petroleum gas facility. The response is fast enough to reach a steady-state condition considering that the composition is one of the variables that has the slowest change, plus a significant decrease in feed, which is down $63 \%$ from the initial condition. The use of PWC at LPGF plant reduced settling time in the deethanizer column by $106 \mathrm{~min}$ (down $47 \%$ ), depropanizer column by 82 min (down $34 \%$ ), and debutanizer column by 132 min (down $43 \%$ ). In addition, there was also a decrease in the maximum overshoot in the deethanizer column by $0.66 \%$, the depropanizer column by $8.42 \%$, the debutanizer column by $6.61 \%$ and eliminating the steady-state error. 


\section{Conclusion}

The conclusion obtained from the design of the Plantwide control in the Liquefied petroleum gas facility is as follows. Application of wide control plant in liquefied petroleum gas facility can increase profit by USD $643 \mathrm{~h}^{-1}(3 \%)$ and decreased energy use by USD $5 \mathrm{~h}^{-1}(5.16 \%)$ Compared to LPGF plant before using PWC. The application of plantwide control in liquefied petroleum gas facility is able to produce stable system response when given disruption of feed flow rate change. This is demonstrated by decreasing slurries time and maximum overshoot as well as eliminating steady-state errors.

\section{References}

1. W. Won, K.S. Lee, Chem. Eng. Sci., 162:21-32(2017).

https://doi.org/10.1016/j.ces.2016.12.069

2. H.E. Alfadala, B.M. Ahmad, A.F. Warsame, CAPE, 20:1279-1284(2005). https://doi.org/10.1016/S1570-7946(05)80055-0

3. T.T. Tuan, L.D. Tufa, M.I.A. Mutalib, A.F.M. Abdallah, Procedia Eng., 148:11041111(2016).

https://doi.org/10.1016/j.proeng.2016.06.601

4. M.L. Luyben, CAPE, 10:31-41(2002). https://doi.org/10.1016/S1570-7946(02)80037-2

5. S. Skogestad, Chem. Eng. Res. Des., 85,1:13-23(2007). https://doi.org/10.1205/cherd06133

6. H. K. Engelien, S. Skogestad, Chem. Eng. Process., 44:819-826(2005). https://doi.org/10.1016/j.cep.2004.06.015

7. S. Skogestad, Comput. Chem. Eng., 28:219-234(2004). https://doi.org/10.1016/j.compchemeng.2003.08.002

8. P.S. Buckley, Techniques of process control, New York: John Wiley \& Sons(1964). https://doi.org/10.1002/aic.690110302

9. L.M. Luyben, B.D. Tyreus, L.W. Luyben, AIChE, 43:3161-3174(1997). https://doi.org/10.1002/aic.690431205

10. V. Minasidis, S. Skogestad, N. Kaistha, Comput. Aided Chem. Eng., 37:101108(2015). https://doi.org/10.1016/B978-0-444-63578-5.50013-X

11. V. Minasidis, J. Jäschke, S. Skogestad, IFAC Proc., 46,32:87-92(2013). https://doi.org/10.3182/20131218-3-IN-2045.00182

12. R. Setiawan, D. Hioe, J. Bao, IFAC Proc., 43,5:451-456(2010). https://doi.org/10.3182/20100705-3-BE-2011.00075

13. J.D. le Roux, S. Skogestad, I.K. Craig, IFAC-PapersOnLine, 49,20:72-77(2016). https://doi.org/10.1016/j.ifacol.2016.10.099

14. A. Faanes, S. Skogestad, J. Process Control., 15:259-271(2005). https://www.sciencedirect.com/science/article/pii/S0959152404000824 